\title{
Effect of Camel Milk's Supplementation on Serum Glucose Levels, Lipid Profile and Body Weight of Alloxan-Induced Diabetic Rats
}

\author{
${ }^{1}$ S.A. Isa, ${ }^{2}$ K.G. Ibrahim and 1 I. Abubakar \\ 1Department of Biochemistry, Usmanu Danfodiyo University, Sokoto, Nigeria \\ 2Department of Physiology, College of Health Sciences, Usmanu Danfodiyo University, Sokoto, Nigeria \\ [*Corresponding Author: : safuntua@udusok.edu.ng, eldersuleiman@yahoo.com; 留: +2347054960123]
}

\begin{abstract}
Cases of diabetes are on the rise in almost every population and epidemiological studies suggest that without proper prevention and control measures, prevalence of the disease will continue to increase globally. The aim of the current study was to investigate the effect of camel milk supplementation on serum glucose, lipid profile and body weight of alloxan-induced diabetic rats. Rats were rendered diabetic by intravenous injection of alloxan (80mg/kg body weight). Diabetic rats showed significantly higer blood glucose levels $(9.68 \pm 1.36 \mathrm{mmol} / \mathrm{L})$. Treatment with camel milk significantly decreases blood glucose levels $(5.33 \pm 0.46) p<0.05$ compared to control. There was a significant increase $(p<0.05)$ in serum total cholesterol, triglyceride, low density lipoprotein cholesterol, very low density lipoprotein cholesterol, and a significant decrease $(p<0.05)$ in high density lipoprotein cholesterol in diabetic untreated rats as compared with control group. However, a significant decrease $(p<0.05)$ in total cholesterol, triglyceride, low density lipoprotein cholesterol, very low density lipoprotein cholesterol, and a significant increase $(p<0.05)$ in high density lipoprotein cholesterol was observed in diabetic treated with camel milk group as compared with diabetic untreated group. No significant change in body weights were observed in all experimental groups during the period of the experiment. The current study demonstrates the efficacy of camel milk in management of diabetes in alloxan induced diabetic rats. This suggests that camel milk may have important implication in the management of diabetes. Further studies are required to elucidate the safety as well as the mechanism of action.
\end{abstract}

Keywords: Camel Milk, Serum glucose, Lipid profile, Diabetes

\section{INTRODUCTION}

Diabetes is the most common metabolic disorder worldwide and its pathogenesis involves insufficient insulin secretion and/or resistance to the action of insulin (Goldstein 2003). The defect in insulin secretion and/or action leads to various metabolic defects that include hyperglycaemia, dyslipidemia, and other forms of tissue damage by several mechanisms (Muoio, 2008). There is an increasing evidence of diabetes in almost every population worldwide and epidemiological studies suggests that without proper prevention and control programmes, prevalence of the disease will continue to increase globally (Alberti et al., 2007). Diabetes affects people all over the world and it has been shown that people with a family history of diabetes are at high risk of developing diabetes (IDF, 2009). Diabetes can be induced chemically using many compounds such as alloxan monohydrate. Alloxan-induced diabetes mellitus is caused by selective pancreatic beta cell toxicity (Rerup, 1970; Sakudelski, 2001). Rats, rabbits and dogs are quite sensitive to alloxan (Typerg et al., 2001).

Diabetes is difficult to cure. However, management of the disease concentrates on keeping blood sugar levels as close to normal without presenting unwarranted patient risk (WHO, 2006). This can be achieved with close dietary management, exercise, and the use of appropriate medications. The currently marketed antidiabetic drugs produce or are associated with negative patient outcomes. For example, thiazolidinediones (TZDs) the most potent antidiabetic drugs are associated with adverse patient outcome. Some of the adverse side effects of TZDs include weight gain due to fluid retention or oedema (Lebovitz and Banerji, 2001), inhibition of vascular smooth muscles and endothelial cells growth and migration (Hsueh and Law, 2001), risk of congestive heart failure, increase risk of myocardial infarction and death from cardiovascular causes (Nissen and Wolski, 2007). These and possible high cost of these drugs make the search for cheaper, effective and safer hypoglycaemic agents worthwhile.

Treatment of diabetes was based on compounds derived from natural products and other types of traditional foods before the advent of insulin therapy. Data on the efficacy and safety of these natural products is scarce. The search for effective and safer hypoglycaemic agents is now an active area of research. 
The use of camel milk as medicine has been known since ancient times. The milk has been shown to possess hypoallergenic (Shabo et al., 2005), and anti-diabetic properties (Agrawal et al., 2003). In addition, Agrawal et al., (2005) reported that camel milk has an adjuvant effect to insulin therapy in controlling diabetes due to the presence of high levels of insulin or insulin like protein.

Camel milk from different part of the world may have different therapeutic properties because the composition of the milk depends on its feed and species (Farah et al., 1992). Other studies also reported variations in certain essential mineral elements and important vitamins (Malik et al., 2008) that are important in management of diabetes and other metabolic disorders. It is therefore the aim of the present research to investigate the efficacy of camel milk obtained from Sokoto, North-West Nigeria in the management of diabetes.

\section{MATERIALS AND METHODS}

All chemicals and reagents used were of analytical grade. Glucose oxidase Kit, Total Cholesterol assay kit, Triglyceride assay kit and HDL-C assay kit were all products of Randox Laboratories, Switzerland. Fresh camel milk samples were obtained from a camel herd (Camelus dromedaries) in SokotoNigeria.

\section{Experimental Design}

Animals: Fifteen clinically normal wistar albino rats of both sexes weighing between 160-200g were used for the study. The rats were purchased from the Department of Biological Science, Usmanu Danfodiyo University, Sokoto, Nigeria and were allowed to acclimatize before the commencement of the experiment. Rats were fed with pelletized growers' feed (Vital feed, Jos, Nigeria). The diet contains 54\% carbohydrates, $13 \%$ fat, $10 \%$ proteins, $20 \%$ fibre, $2 \%$ normal supplement and $1 \%$ vitamin and water. The rats were allowed access to water ad libitum before and during the experimental period.

Induction of Diabetes: Induction of diabetes was by intravenous injection of alloxan (Black et al., 1980). Fresh solution of alloxan was prepared prior to experiment and rats were administered $80 \mathrm{mg} / \mathrm{Kg}$ body weight of the prepared solution. After one week of alloxan injection, diabetes was confirmed through the measurement of blood glucose levels from tail vein blood using glucometer (Prestige). Rats with blood glucose concentration $\geq 8.0 \mathrm{mmol} / \mathrm{L}$ were considered for the experiment.
Grouping: The animals were grouped into 3 groups of five rats each. Group 1 (non diabetic-non supplemented) to which no alloxan induction no milk supplementation. Group 2 (diabetic-non supplemented) to which diabetes was induced but no milk supplementation. Group 3 (diabetic-treated) to which diabetes was induced and supplemented with fresh camel milk. Each rat in Group 3 was treated with $1 \mathrm{ml}$ of camel milk daily using $1 \mathrm{ml}$ syringe for oral administration for 2 weeks. The dose was then increased to $2 \mathrm{ml}$ for additional 2 weeks.

Blood and Serum Collection: After four weeks of the treatment, the rats were fasted for 12 hours, anesthetized using chloroform and then sacrificed by decapitation using razor blade. Blood sample was collected through cardiac puncture in clean dry test tubes (without any anticoagulant) and allowed to clot at room temperature for 30 minutes. The serum was separated by centrifugation at $4000 \mathrm{~g}$ for 10 minutes and were saved in aliquots and stored at $-20^{\circ} \mathrm{C}$ for further analysis.

\section{Biochemical Analysis}

Biochemical analytes were estimated using commercially available kits as follows. Blood glucose level was determined using glucose oxidase method (Trinder,1969), Serum total cholesterol (TC) (Allain et al., 1974), serum triglycerides (TAG) (Tietz, 1990), serum High Density Lipoprotein (HDL-C) (Burstein et al., 1980), Serum Low Density Lipoprotein cholesterol (LDL-C) (Friedwald et al., 1972) and serum Very Low Density Lipoprotein cholesterol (VLDL-C) (Friedwald et al., 1972). Atherogenic index was calculated as ratio of LDL-C to HDL-C (Abott et al., 1988).

\section{RESULTS AND DISCUSSION}

Effect of Camel Milk Supplementation on Body Weight: Body weight of rats in control group was $266.25 \pm 25.49 \mathrm{~g}$, diabetic untreated $242.33 \pm 9.56 \mathrm{~g}$, and in diabetic treated was $253.45 \pm 22.20 \mathrm{~g}$. There were no statistically significant difference $(p>0.05)$ in the body weights of all the groups.

Effect of Camel Milk Supplementation on Serum Glucose Levels of alloxan-induced diabetic Rats Blood glucose level in camel milk treated group when compared to diabetic untreated was $5.33 \pm 0.46$ and $9.68 \pm 1.36 \mathrm{mmol} / \mathrm{L}$ respectively. As shown in Figure 1 , giving camel milk to alloxan-induced diabetic rats was associated with decrease in blood glucose levels.

The significant decrease in blood glucose level in diabetic rats treated with camel milk could be due to 
the reported high levels of insulin or insulin like protein in camel milk (Farah 1993; Agrawal et al., 2003). Other studies attributed hypoglycaemic effect of camel milk by its potential to either increase the effect of insulin or by increasing the release of insulin from the pancreatic beta-cells (Sboui et al., 2010).

Table 1: Initial and final body weight of alloxaninduced diabetic rats treated with or without camel milk.

\begin{tabular}{lll}
\hline Groups & \multicolumn{2}{c}{ Body weight (g) } \\
\cline { 2 - 3 } & Initial & Final \\
\hline Group 1 & $245.20 \pm 17.89$ & $266.25 \pm 25.49$ \\
Group 2 & $251.70 \pm 10.15$ & $242.33 \pm 9.56$ \\
Group 3 & $265.00 \pm 24.13$ & $253.45 \pm 22.20$ \\
\hline Van
\end{tabular}

Values are mean \pm SEM of body weight of alloxan induced diabetic rats supplemented with or without camel milk for 28 days.

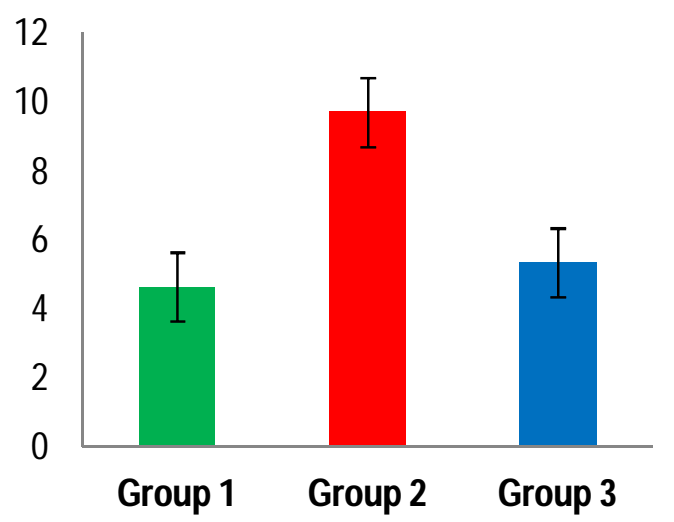

Figure 1: Serum blood glucose concentration $(\mathrm{mmol} / \mathrm{L})$ of alloxan-induced diabetic rats supplemented with camel milk.

Values are expressed as mean \pm SD. *denotes $\mathrm{P}<0.05$ compared to diabetic untreated. Group 1=control; Group 2=diabetic non supplemented; Group 3=diabetic supplemented

\section{Effect of Camel Milk Supplementation on serum Lipid Profile of alloxan-induced Diabetic Rats}

The effect of camel milk supplementation on serum lipid profile is presented in Table 2. There was a significant increase $(p<0.05)$ in serum total cholesterol (TC), triglycerides (TAG), low density lipoprotein cholesterol (LDL-C), very low density lipoprotein cholesterol (VLDL-C), and a significant decrease $(p<0.05)$ in high density lipoprotein cholesterol (HDL-C) in diabetic untreated rats as compared with control group. However, a significant decrease $(p<0.05)$ in TC, TAG, LDL-C, VLDL-C, and a significant increase $(p<0.05)$ in $\mathrm{HDL}-\mathrm{C}$ was observed in diabetic treated with camel milk group as compared with diabetic untreated group.

There is clear evidence of the negative impact of diabetes on the prevalence, severity and prediction of cardiovascular diseases. Several epidemiological studies have shown a consistent association between hyperglycemia and cardiovascular diseases (Balku et al., 2004). In addition, insulin deficiency as a result of diabetes leads to abnormalities in lipid metabolism (Arkkila et al., 2001). In this study, alloxan-induced diabetic rats showed increased hypercholesterolemia, hypertrigly-ceridemia and decreased levels of HDL-C (Table 2). These results are in agreement with previous reports (Mathe 1995; Hassan and Emam, 2012). Our result shows that treatment with camel milk is associated with a significant decrease in triglycerides level compared with untreated (Table 2). Hypertriglyceridemia is a common feature of diabetes. Lipoprotein lipase is the enzyme that hydrolyses triglycerides. However, insulin was shown to activate this enzyme (Arrkila et al., 2001) and because of the high levels of insulin in camel milk, this may be a possible cause of the reduction of the triglycerides levels in the treated group.

Administration of camel milk to diabetic rats brought about a significant decrease in circulating LDL-C and total cholesterol (Table 2). Under normal conditions, LDL-C is cleared from the circulation by reuptake in the liver through receptor mediated uptake (Tiwari et al., 2008). A well-known risk factor for the development of diabetes and cardiovascular disease is lipid accumulation in non-adipose tissues (van Herpen \& Schrauwen-Hinderling, 2008). Thus, the increase in LDL-C seen in diabetic rats may be due to increased mobilization of free fatty acids, as well as defect in LDL-C receptors. Meanwhile, there was a significant increase in HDL-C levels in rats treated with camel milk compared to untreated (Table 2). Excess cholesterol is removed from the circulation by HDL (Stermerman, 2000) and it is regarded as good cholesterol due to the fact that it is associated with decreased tendency of development of atherosclerosis (Rader, 2006) a risk factor for the development of diabetes.

\section{Effecct of camel milk supplementation on atherogenic index}

The result of the effect of camel milk supplementation on atherogenic index is presented in Table 2. The result shows that camel milk's supplementation is associated with a decrease in atherogenic index compared to untreated. 
Table 2: Serum lipid profiles \& Atherogenic index of alloxan-induced diabetic rats supplemented with camel milk

\begin{tabular}{llll}
\hline Parameters & Group 1 & Group 2 & Group 3 \\
\hline TC $(\mathrm{mg} / \mathrm{dl})$ & $208.29 \pm 23.11$ & $479.41 \pm 57.56^{\star}$ & $264.78 \pm 30.27^{\times}$ \\
TAG $(\mathrm{mg} / \mathrm{dl})$ & $110.00 \pm 14.14$ & $650.00 \pm 104.08^{\star}$ & $192.00 \pm 19.85^{\times}$ \\
HDL-C $(\mathrm{mg} / \mathrm{dl})$ & $152.57 \pm 17.19$ & $114.69 \pm 4.86^{*}$ & $220.82 \pm 14.59^{\star}$ \\
LDL-C $(\mathrm{mg} / \mathrm{dl})$ & $33.72 \pm 4.24$ & $234.72 \pm 37.26^{\star}$ & $5.59 \pm 2.56^{\star}$ \\
VLDL-C (mg/dl) & $22.00 \pm 2.83$ & $130.00 \pm 20.82^{\star}$ & $38.4 \pm 3.97^{\star}$ \\
Atherogenic index & 0.22 & 2.05 & 0.025 \\
\hline
\end{tabular}

Values are means \pm S.E. ( ${ }^{*}$ denotes $P<0.05$ compared to control; ${ }^{\times}$denotes $P<0.05$ compared to diabetic untreated).

\section{CONCLUSION}

The current study demonstrates the efficacy of camel milk in management of diabetes in alloxan induced diabetic rats. This suggests that camel milk consumption may have important implication in the management of diabetes in human. Further studies are required to elucidate the safety as well as the mechanism of action of the agent(s) in camel's milk.

\section{REFERENCES}

Abbott, R.D., Wilson, P.W., Kannel, W.B. and Castelli, W.P. (1988).High density lipoprotein cholesterol, total cholesterol screening and myocardial infarction. The Framingham study. Atherosclerosis, 8: 207-211.

Agrawal, R.P., Beniwal, R., Sharma, S., Kochar, D.K., Tuteja, F.C. and Ghorui, S.K (2005). Camel milk as an adjunct to insulin therapy improves longterm glycemic control and reduction in doses of insulin in patients with type-1 diabetes - a 1 year randomized controlled trial. Diabetes Research Clinical Practice 68:176-177.

Agrawal, R.P., Swami, S.C. and Beniwal, R. (2003). Effect of camel milk on glycemic control, risk factors and diabetes quality of life in type 1 diabetes: A randomized prospective controlled study. Journal Camel Practice Research, 10(1): 45-50.

Alberti, K.G., Zimmet P. and Shaw, J. (2007). International Diabetes Federation: A Consensus on Type 2 Diabetes Prevention. Diabete Medicine, 24(5): 451-463

Allain,C.C., Poon, L.S., Chan, C.S.G., Richmond, W. and Fu, P.C. (1974). Enzymatic determination of total serum cholesterol. Clinical Chemistry, 20: 470.

Arkkila, P.E., Koskinen, P.J. and Kantola, I.M. (2001). Diabetic complications are associated with liver enzyme activities in people with type I diabetes. Diabetes. Research Clinical Practice, 52: 113118.

Balku, B., Hu, G., Qiao, Q., Tuomilehto, J., BorchJohnsen, K. and Pyoraja, K. (2004). Prediction of the Risk of Cardiovascular Mortality Using a Score that Includes Glucose as a risk factor.
The DECODE study. Diabetologia, 47(12): 2118-2128.

Black, H.E., Rosenblum, I.Y. and Capen, C.C. (1980). Chemically induced (streptozotocin-alloxan) diabetes mellitus in the dog. Biochemical and ultrastructural studies. American Journal of. Pathology, 98: 295-310.

Burstein, M., Scholnick, H.R. and Morfin, R. (1970). Rapid method for the isolation of lipoproteins from human serum by precipitation with polyanions. Journal of Lipid Research, 11: 583595.

Davis, W.A., Knuiman, M.W., Hendrie, D. and Davis, T.M. (2006). The Obesity Driven Rising Costs of Type 2 Diabetes in Australia: Projections From the Fremantle Diabetes Study. Internal Medicine Journal, 36(3):151-161.

Farah, Z. (1993). Composition and characteristics of camel milk. Journal of Dairy Research, 60: 603626.

Farah, Z., Rettenmaier, R. and Atkins, D. (1992). Vitamin content of camel milk". International Journal for Vitamin and Nutrition Research, 62(1): 30-33.

Goldstein, B.J. (2003). Insulin Resistance: From Benign to type 2 diabetes mellitus. Review Cardiovascular Medicine, 4(Suppl 6): S3-S10

Friedewald, W.T., Levy, R.I. and Fredrickson, D.S. (1972). Estimation of LDL-C in plasma without the use of the preparative ultracentrifuge. Clinical Chemistry, 18(6): 499-502

Hassan, N.S. and Emam, M.A. (2012). Protective Effect of Camel Milk and Ginkgo biloba Extract Against Alloxan-Induced Diabetes in Rats. Journal Diabetes Metabolism 3: 231. doi:10.4172/2155-6156.1000231

Hsueh, W.A. and Law, R.E. (2001). PPARy and Arteriosclerosis: Effect on Cell Growth and Movement. Arterioscler. Thrombosis Vascular Biology, 21(12):1891-1895

International Diabetes Federation (IDF) 2009. The IDF Consensus worldwide definition of the metabolic syndrome .Available at: http://www.diabetesvoice.org/files/attachments/a rticle 361 en.pdf 
Lebovitz, H.E., and Banerji, M.A. (2001). Insulin Resistance and its Treatment by Thiazolidinediones. Recent. Progress. Hormone Research, 56: 265-294

Malik, S.Y.H., Sana, I.G. and Richard, K.R. (2008).Seasonal variations in the chemical composition of camel milk in Jordan. Journal of Dairy Research, 75: 8-12.

Mathé D (1995) Dyslipidemia and diabetes: animal models. Diabete Metabolism, 21: 106-111.

Muoio, D.M. and Newgard, C.B (2008). Molecular and metabolic mechamism of insulin resistance and B-cell failure in types 2 diabetes. Nature Review Molecular Cell Biology, 9: 193-205.

Nissen SE, Wolski K (2007). Effect of Rosiglitazone on the risk of myocardial infarction and death from cardiovascular causes. New England Journal Medicine, 356(24): 2457-2471.

Rader, D. J. (2006). Molecular regulation of $\mathrm{HDL}$ metabolism and function: implications for novel therapies. Journal Clinical Investigation, 116: 3090-3100.

Renup, C.C. (1970). drugs producing diabetes through damage of the insulin secreting cells. Pharmcology Review, 22: 485-518.

Sboui A., Djegham M., Khorchani T., Mohamed Hammadi M., Barhoumi K, Omrane Belhadj O (2010). Effect of camel milk on blood glucose, cholesterol and total proteins variations in alloxan-induced diabetic dogs International Journal Diabetes and Metabolism, 18:5-11.

Sakudelski, T (2001). Mechanism of alloxan and streptozocin action in beta cells of the rat pancreas. Physiological Research, 50(6): 536546.
Shabo, Y. R. Barzel, M. Margoulis and R. yagil, (2005). Camel milk for food allergies in children. Israel. Medical Association. Journal, 7: 796-798.

Stemerman, M. B. (2000). Lipoprotein effects on the vessel wall. Circulation Research, 86, 715-6. Lipoprotein effects on the vessel wall.

Trinder, P. (1969). Determination of blood glucose in blood using glucose oxidase with an alternative oxygen acceptor, Annals of Clinical Biochemistry, 6: 24-25.

Tietz, N.W. (1990). Serum triglyceride determination. In: Clinical guide to laboratory tests, second edition, W.B. Saunders Co, Philadelphia, USA, Pp 554-556

Tiwari, R.I., Singh, V. And Barthwal, M.K. (2008). Macrophages: An Elucive Yet emerging Therapeutic Targets of Atherosclerosis. Medicinal Research Reviews, 28(4): 483-544.

Typerg, B, Anderson A, Hakan Borgla (2001). Species differences in susceptibility of transplanted and cultured pancreatic islets to the B-cell. General Comparative Endocrinology. 122: 238-251.

van Herpen NA, Schrauwen-Hinderling VB (2008). Lipid Accumulation in Non-adipose Tissue and Lipotoxicity. Physiology and Behavior, 94(2):231-241.

World Health Organization (WHO) (2006). Definition and diagnosis of diabetes mellitus and intermediate hyperglycemia: report of a WHO/IDF consultation. Geneva: p. 21.

Yach D, Stuckler D, Brownell KD (2006). Epidemiologic and Economic Consequences of the Global Epidemics of Obesity and Diabetes. Nature Medicine, 12(1):62-66. 